\section{Issues with transferring knowledge acquired through workplace pedagogical interventions to on-the-job application}

\author{
Procknow, Greg $\varangle$
}

University of Regina, Canada (prockngr@uregina.ca)

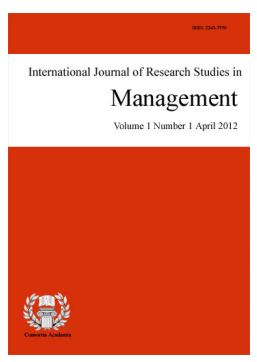

ISSN: 2243-7770 Online ISSN: 2243-7789

\begin{abstract}
Workplace educational interventions cunningly contrived to augment an employee's knowledge and understanding of requisite tasks enveloped in their prescribed job description, are consistently proven to be ineffective when actually applied to on-the-job performance. The current study documented here looks at a Canadian product development/distributor and the issues this workplace has with new employees transferring efficaciously with what they have recently learned in training to job performance. Furthermore, the literature is surveyed extensively to ascertain what the current state of training transfer is in today's varied workplaces. Recommendations for workplace educators are provided to help unburden the hidden intricacies inherent in all training transfer situations.
\end{abstract}

Keywords: workplace education; training transfer; human resource development; knowledge acquisition; job performance 


\section{Issues with transferring knowledge acquired through workplace pedagogical interventions to on-the-job application}

\section{Introduction}

Workplace leaders have an insatiable expectation for their staff to deliver consistently pristine performance. But how does one acquire the skills necessary to do such great work? It is simple, workplace education. Workplace pedagogical formats are intended to produce studious cogs who take punctilious care in performing their requisite duties (Illeris, 2011). Not only indentured to workplace efficacy, organizations learned employees sharply differentiate a learning organization from an unlearning organization (Malloch, 2010). In this study, dichotomously, both quantitative and qualitative research has been appropriated in this article.

From well-known international conglomerates, to domestic nonprofit organizations, issues with training knowledge transfer surface in all walks of institutionalized performance. This study delves into the literature on training transfer, and attempts to confirm the literatures conclusions by producing the findings of a field observation made of a Canadian product manufacturer/distributor's new employees being trained by experienced trainers. Beyond peradventure, the strength of workplaces today is dependent upon the success of their human capital. But what if their employees are void of the habitual and imperative knowledge ever so needed to perform the job's task cycle with 100 percent efficacy?

\subsection{Research Questions}

1. What claims does the available literature make about pedagogical transfer in the workplace?

2. What conclusions can we infer from the following Canadian warehouse observational study?

3. What are conclusively proven strategies to help foster positively a learner's knowledge acquisition?

\section{Training transfer}

To define simply, training transfer, otherwise construed as transferring knowledge encompassed by a training program, entails the learner (trainee, student, and many others) channeling their learnt knowledge into improving task application in total fulfillment of their prescribed job cycle (Saks \& Haccoun, 2008). Comparably similar to a science student acquiring new obligatory information from their professors lectures to apply at a later date on their science examinations. Where there is pedagogy, there will always be accompanying knowledge transfer issues. The next section proffers insights on what is the current state of training transfer in today's business operations.

\subsection{Training transfer in its current state}

Transferring knowledge from what is provided for in a educational intervention to workplace hands-on use is a concerning problem in today's workplaces. Bates (2003) posits that there is prevalent an accumulated burden of training transfer neglect (failure in some cases) stemming from what is learned during a prescribed workplace training intervention to what ideal performance is actualized when training is transferred to the job. Bates (2003) proffers a tidbit of empirical evidence from Garavaglia's (1993) study finding that "as little as [ten] percent of the investment in training pays off in performance improvements". Bates continues by providing a composite look at confirmed research studies and the conclusions inferred from these studies on what influences, facilitates and impedes learning transfer: "there is a good deal of room for more research and better practice in training transfer" (p.179). Saks and Haccoun (2008) too strongly agree that training transfer is a problematic phenomenon "research has shown that many trainees do not actually apply what they learn in training on the 
job" (p. 263).

Bates (2003) provides the statistic of 10 percent of training investment actually pays off in performance improvements other studies suggest between 60 and 90 percent of what is learned in training is not applied on the job (Phillips, J. J. \& Phillips, P. P., 2002). Comparing and contrasting these two statistics makes it extremely easy to agree with the claims against training transfer; that when we have a study that proposes up to 90 percent of what is learned in training is not applied in actual practice, and 10 percent of total training investment is realized in increased performance in another study, it opens one's eyes to the fact that companies and other institutions that invest in training need to really start formulating plans to translate these pedagogical interventions into greater profitability as a result of improved performance.

\subsection{Training transfer neglect in the available literature}

Although avoiding diatribe, Bates (2003) does make an inquiry into the absence of profound knowledge on how to ensure a successful learning transfer process. Bates (2003) postulates "although the progress is promising" the research compiled to date has provided "limited knowledge about which factors have the greatest impact on the transfer of training and about how these factors affect transfer behavior under different conditions and different kinds of training" (p.178).

\subsection{Baldwin and Ford's Model of the Transfer of Training Progress (1988)}

The earliest of training transfer interventions, is Baldwin and Ford's Model of the Transfer of Training Progress (1988). Perhaps a successful model being utilized by today's researchers; this model according to Saks \& Haccoun (2008) "provides a number of practical implications for facilitating and improving the transfer of training" (p. 271). Doing research on this model and comparing and contrasting to Bates (2003) arguments in terms of which input variables complicate the transfer of training process have three things in common with Baldwin and Fords (1988) model. Bates (2003) proposes trainee characteristics, training design, and work environment; as we can see below in figure 1, Bates (2003) is one of the same understandings with Baldwin and Ford.


Figure 1. Baldwin and Ford (1988) 


\section{Research methodology}

\subsection{Research design}

The ensuing observational study was designed as a quantitative methodology. Typically, quantitative research can utilize various different designs, for this study, field observations and experimental designs were used. An experimental design, according to Lewin (2005) is the "primary approach in the positivist paradigm" (p. 216). A longitudinal design was employed within a naturalistic work environment, where the independent variable (workplace job performance) and how the dependent variable (trainee's knowledge) is influenced by workplace learning bestowed on the latter by mandated workplace educators.

\subsection{Task analysis}

\subsubsection{Identifying the target jobs}

The task analysis is the process of obtaining information about a job by determining the duties, tasks, and activities involved and the knowledge, skills, and abilities required performing the tasks assigned to them (Saks, 2008). There are two actions involved in a task analysis according to Saks (2008) that should be engaged prior to data being enumerated: 1.) Identify the target jobs; 2.) Obtain a job description. Upon preliminary consultation with both organizational managers of the two selected samples, it was necessary to ascertain which jobs were contributing to the perceived performance problems. Having first inquired for a list of jobs; management was observed performing each task as so the researcher could get a better understanding of how each task action is to be correctly performed. During this observation, management was asked to describe the importance of each task respectively.

\subsubsection{Obtain job descriptions}

Once the jobs were identified, designing job aids for those jobs that were absent one, was integral to get a better comprehension of the jobs branching tasks, and responsibilities; in addition to, this informs the researcher which of aforementioned job idiosyncrasies are fundamental to effectively satisfy each job requirement accordingly. The researcher was trained on how to perform each task. Copiously, notes were gathered to serve as auxiliary aids in the cultivation of job descriptions, to be used in later research phases of the study.

\subsection{Research instruments}

As mentioned above the researcher was engaged in participant observation. The participant observer needed to acquire insights into the activities, behaviors and characteristics of each job being performed. To not attract attention, with the explicit permission of management, the observer worked within each position for a day, as to get absorbed into the culture of the organization. Both structured and unstructured observations were employed after the observer notified ignorant employees of the reason they would be observed. Structured observations were tailored for trainee observations: a schedule was established with the trainees pre-testing. Contrastingly, unstructured observations were used when observing trainees perform the each job cycle, holistically, with no schedules formulated pre-testing. The researcher wished to experience the trainer's performance ill-prepared and unrehearsed. Observations enabled the researcher to minimize the influence and presence perceived by the observed allowing them to work without interruptions.

\subsection{Research participants}

\subsubsection{Supervisor/Trainers}

Four warehouse/retail supervisors amid a Canadian product development/distribution center were observed performing the job cycle of each observed warehouse operations position. Trainers with more than one year of 
experience as trainers were selected. These were the organizations subject matter experts (SME), and were often noted as being the sole group of trainers responsible for all warehouse training.

\subsubsection{Novice Employees}

For the purpose of this study four newly assimilated employees participant to the job cycles under observation, were to be assessed how effective their training knowledge was by being observed in practice.

\section{Results and discussions}

\subsection{What conclusions can we infer from the following Canadian warehouse observational study?}

\subsubsection{Trainers were inadequately imparting knowledge}

In one of the organization's operational areas, the job observed was sorting of goods. Of the seven tasks deemed important for most effectively sorting products, trainer \#1 scored a three out of seven and trainer \#2 a four out of seven. If the first trainer was observed training the researcher on 49 percent of the requisite tasks, and the second trainer 57 percent then really how effective will this training be for new recruits. If the recruit is only being educated in 49-57 percent of the tasks of each job, then inevitably issues with performance will ensue.

\section{Table 1}

Trainers observed knowledge results

\begin{tabular}{lccccc}
\hline \multicolumn{1}{c}{ Operations Area } & Trainer \#1 & Trainer \#2 & Trainer \#3 & Trainer \# 4 & \# of important tasks \\
\hline Product development & 4 & 4 & 7 & 8 & 11 \\
Product recall sort & 3 & 4 & 4 & 4 & 7 \\
Product repack & 5 & 4 & 1 & 3 & 7 \\
Client greeter & 4 & 3 & 4 & 4 & 6 \\
Client room door monitor & 3 & 4 & 2 & 2 & 5 \\
Client room security & 3 & 2 & 2 & 3 \\
\hline
\end{tabular}

Each trainer was observed performing each job cycle three or more times. The numbers per trainer are their averages from the three times the job cycle was observed. Their performance results were conservatively compared to the number of important tasks pre-established in step two of the task analysis, so if trainer \#3 is employed in the position of gate greeter, had scored a 3 out of 6 that means that they on average deviated from their required job criteria 50 percent of the time.

\subsubsection{Training knowledge insufficient and incomplete}

To validate the findings, the researcher observed four aspirants (observed in their second-fifth day on the job) to accurately deduce how effective they were retaining the requisite training information ceded to them from supposedly experienced trainers. Four trainees were observed performing each job, trainers 1-4 instructed them on; the results of this observation are appositely illustrated in table 2.

Both observations and self-administered tests were used to correlate this data. Each trainee was observed performing the task three or more times. The numbers per observed are their averages from the three times the job cycle was performed. This was done to ensure the data's validity. Their performance results were compared to the number of important tasks already pre-established in step two of the task analysis; for instance if trainee \#3 in the position of client greeter scored a 4 out of 6 they were noted to have on average made a 44 percent deviation from their job criteria while performing their 66 percent of their job's entailments correctly. Naturally, 
the trainers outperformed the trainees when observed performing each job's task cycle, but in some areas, shockingly not by that much. Surprisingly, product development trainers performed an average of 5.75 out of 11 job tasks correctly, where trainees scored 6 out of 11. It was in the product recall sort department trainers outperformed substantially new trainees: trainers averaged 4.25 , as trainees averaged a 3.75 out of a potential 7 .

Table 2

Trainees' observed/self-recorded applying new job knowledge

\begin{tabular}{lccccc}
\hline \multicolumn{1}{c}{ Operations Area } & Trainer \#1 & Trainer \#2 & Trainer \#3 & Trainer \# 4 & \# of important tasks \\
\hline Product development & 5 & 4 & 8 & 7 & 11 \\
Product recall sort & 3 & 5 & 4 & 3 & 7 \\
Product repack & 3 & 4 & 4 & 3 & 7 \\
Client greeter & 3 & 3 & 4 & 2 & 6 \\
Client room door monitor & 3 & 4 & 2 & 3 & 5 \\
Client room security & 2 & 2 & 2 & 2 & 3 \\
\hline
\end{tabular}

\subsubsection{Tacit knowledge used by trainers}

The trainers were concluded to have been using their tacit knowledge of each job cycle in the training of new recruits: since no job descriptions or aids were observed being utilized by the trainer when training new employees. Trainer tacit knowledge can hinder the process of knowledge acquisition. Tacit knowledge can be defined as the knowledge demonstrated by someone (in the following example: the trainer) in their role that stems from their increased experience working within that position; those that employ tacit knowledge have their own self-taught tricks on how to perform the job quicker, and self-assuredly more efficiently.

Procknow (2011) explores the application of tacit knowledge in the training process of new volunteers in a Canadian nonprofit food bank. In this study fifteen volunteer team leads were observed (team leads in this setting were staff sanctioned trainers) and eleven were observed training new trainees employing their tacit knowledge, not using any job descriptions or job-training checklists. They relied on their experience and exclusive task know-how to train the new volunteers with. The trainees then had their performance evaluated; for those trainees who had trainers who relied on their tacit knowledge were observed underperforming when left to work individually.

Additional, research suggests this in fact could be a possibility especially as a pre-training negative influence. If the manager/supervisor fails to foster a learning culture and thus provides little support for the employee to undergo performance improvement then this could have adverse negative implications on the employees (trainee) motivation to fully participate in the training program. Saks \& Haccoun (2008) support this claim by suggesting "managers need to show their support for training before an employee is sent to a training program" (p. 275). "managers can facilitate the transfer of training during training by showing their support for training" (p. 277). Management and supervisor support pre-training will create the necessary auxiliary support crutch the trainee requires: Bates (2003) suggests "enhancing transfer with interventions that are straightforward and inexpensive (for example, supervisors communicating persuasive messages to trainees about the skill improvement and survival value of training" (p. 182).

\section{Recommendations}

What are conclusively proven strategies to help foster positively a learner's knowledge acquisition? Bates (2003) proffers insights on what tools can be manipulated to alleviate this neglect of training transfer from a pedagogical intervention to workplace applicability. Below are three concepts/tools used to help the training 
transfer process be effective: Learning transfer system inventory (LSTI); Locus of control; and Relapse prevention.

\subsection{Learning transfer system inventory (LTSI)}

Learning Transfer System Inventory (LTSI) diagnoses the variables negatively affecting transfer of training. It is based on three components: (a) a set of variables that influence transfer; (b) a diagnostic instrument; (c) and a change process model. Bates (2003) attributes LTSI as the foremost breakthrough in the evolution both in transfer practice and research. Viewing LTSI from a research perspective; "it provides an organized framework in which systematic research can be conducted, and is attended by a promising set of measures that can facilitate valid-cross study comparisons and consequently add to a more complete understanding of the transfer process" (p. 196). In regard to practice, LTSI can be used as "an accessible tool organizations can use to diagnose, understand, and improve their learning transfer systems" (p. 196). It is clear that this mechanism is efficient at providing the researcher a simple and quick process to diagnosticate transfer system issues. Larson (2010) as part of her doctoral dissertation performed a study on transfer of learning and the effects of different instruction methods used in software application training; LTSI in this study measured transfer of learning 30 and 60 days after three randomly selected groups were to participate in software training; LTSI measured accurately that the "findings did not demonstrate statistical significance or transfer of learning between [the different] instruction methods" (p. 4).

\subsection{Locus of control}

Bates (2003) finds promise in the transfer-related factor 'locus of control'. Locus of control is described as "the extent to which people attribute cause or control of events to themselves (internal locus of control) or to environmental factors"; these environmental factors e.g. luck or fate, we are to consider as external locus of control (Kren 1992, p. 990). This personality dimension Bates links with high academic achievement, success in one's job, applying ones knowledge newly gained from training, and in one study he cites Tziner, Haccoun, and Kadish (1987) speculating that locus of control could possibly interface with relapse prevention (a transfer-design methodology) as to influence the transfer process. When the trainee possesses a positive locus of control as a pre-training attribute can indissolubly transpire into greater transfer of training application: it can be incredibly reinforcing to go into a training program with the belief that "I am in control of what I learn, and what I eventually apply in practice". Cheng (2001) would agree that in a training situation, those trainees that believe they can control the "provision of organizational outcomes" with higher probability will successfully apply training content to their jobs (p. 107).

\subsection{Relapse intervention}

Bates (2003) suggests Relapse prevention as a valuable transfer strategy any learning organization could avail oneself of. Relapse prevention simply facilitates training transfer by aiding the learners understanding of the relapse process (or reverting back to pre-training undesired behaviors), and offers coping strategies. Relapse prevention is the foremost front runner of the transfer of training interventions proposed by scholars. By instructing the trainee how to anticipate transfer obstacles in the workplace and by providing them with the withstanding strategies to supersede impediments, helps to immunize them from reverting back to their undesired pre-training behavior. Relapse intervention would too be extremely useful in those workplaces where support for training is low. Burke's (2001) study suggests that relapse prevention interventions can be seen as immensely effective when the transfer climate is not very supportive of the training intervention being proposed pre-training or post-training. A 1991 study conducted by Tziner et al. (1991) suggested that those with internal locus of control who "benefited from a relapse prevention module" had shown higher levels of training content mastery; that they were with higher probability likely to employ these trained skills in their entirety in the workplace. 


\section{Conclusions and implications for Workplace Pedagogical Facilitators}

The interventions conjectured best for diagnosing what is disrupting and/or encouraging the aptitude of the transfer system are valid and exorbitantly bolstered by a variegated researcher pool. The implications of preventable training issues are far-reaching and far too costly for organizations to keep investing in training programs for their employees or in Procknow (2011) case volunteers, when they prove fruitless. Transfer of training is an exceedingly importunate concern for workplace educators and HRD personnel. If both HRD pedagogues and learning interventions are bequeathed to improve personal and professional wherewithal of staff, and add vigor to organizational performance, than having a more embedded understanding of their proposed transfer system is not so much a necessity but a requirement for success. Furthermore, with their only being a 10 percent transfer of training success rate reported in the research, reflecting negatively on HRD, that perhaps they are auspicious at doing 10 percent of their job correctly when it comes to overseeing learning in the workplace. Broad and Newstrom (1992) study on transfer of training, they remark U.S companies spend billions of dollars annually on HRD for their employees. Furthermore, taking into account miserable projections that less than 20 percent of what is learnt in workplace erudition is applied by the employee on the job. Broad and Newstrom (1992) infer that in order for companies to stay competitive in the global marketplace, and to forge a highly competent workforce, ameliorating transfer of training must become Human Resources Development's top priority: "our multibillion-dollar training industry has to show that HRD investments pay off in improved performance on the job" (p. ix).

\section{References:}

Bates, R. (2003). Training transfer: Progress and prospects. In A. M. Gilley, J. F. Callahan, \& L. L. Bierema (Eds.), Critical issues in HRD: A new agenda for the twentieth century (pp. 179-197). Cambridge, MA: Perseus Publishing.

Baldwin, T. T., \& Ford, J. K. (1988). Transfer of training: A review and directions for future research. Personnel Psychology, 41, 63-105. doi: 10.1111/j.1744-6570.1988.tb00632.x <http://dx.doi.org/10.1111/j.1744-6570.1988.tb00632.x >

Broad, M. L., \& Newstrom, J. M. (1992). Transfer of training: Action-packed strategies to ensure high payoff from training investments. Reading, MA: Addison-Wesley.

Burke, L. A. (2001). Training transfer: Ensuring training gets used on the job. In L. A. Burke (Ed.), High-impact training solutions: Top issues troubling trainers (pp. 89-116). Westport, CT: Quorum Books.

Cheng, E. W. L. (2001). A review of transfer of training studies in the past decade. Personnel Review, 30(1), 102-118. doi:10.1108/00483480110380163 <http://dx.doi.org/10.1108/00483480110380163>

Illeris, K. (2011). The fundamentals of workplace learning: understanding how people learn in working life. Taylor and Francis.

Lewin, C. (2005). Elementary quantitative methods. In B. Somekh \& C. Lewin, Research methods in the social sciences (pp. 215-225). London: Sage.

Malloch, M. (2010). The Sage handbook of workplace learning. CA: Sage.

Phillips, J. J., \& Phillips, P. P. (2002). 11 Reasons why training and development fails and what you can do about it. Training, 39(9), 78-85.

Procknow, G. (2011). Three Stages of Volunteer Learning. Canadian Journal of Volunteer Resources Management, $19(1), 5-7$.

Saks, A., \& Haccoun, R. R. (2008). Managing performance through training and development (4th ed.). Nelson Series in Human Resources Management.

Tziner, A., Haccoun, R. R., \& Kadish, A. (1991). Personal and situational characteristics influencing the effectiveness of transfer of training improvement strategies. Journal of Occupational Psychology, 64, 167-177. doi: 10.1111/j.2044-8325.1991.tb00551.x <http://dx.doi.org/10.1111/j.2044-8325.1991.tb00551.x > 